\title{
Cognitive approach to the analysis and choice of innovation strategies of the enterprises
}

\author{
Robert A. Karayev \\ Institute of Cybernetics of the National Academy of Sciences, Baku, Azerbaijan
}

Email address:

karayevr@rambler.ru

\section{To cite this article:}

Robert A. Karayev. Cognitive Approach to the Analysis and Choice of Innovation Strategies of the Enterprises. Journal of Investment and Management. Vol. 3, No. 1, 2014, pp. 1-6. doi: 10.11648/j.jim.20140301.11

\begin{abstract}
The article considers the problem of the analysis and choice of innovation strategies of the small and medium-sized enterprises in modern complicated unstable economic conditions. Difficulties of solving this problem at the early conceptual design stage interfaced to high uncertainty and risk are marked. For the problem decision are offered the cognitive technologies of support which are today the most effective and perspective tools for analysis and management of ill-structured problematic situations and, in particular, problematic situations of choice of enterprise innovation strategies. The proposed technology allows building a unified multi-disciplinary platform that integrates instrumental potentials all known business-concepts of innovation management. "Inference mechanism", developed as a part of this technology allows investigating the long-term dynamics of innovation strategies in the context of changing business environment and strategy targets of stakeholders. The aim of the article is to demonstrate the applied capacity of cognitive technologies, specifics of their building and the prospects of their use in the real conditions of innovation business.
\end{abstract}

Keywords: Small and Medium-Sized Enterprise, Innovation Strategies, Analysis and Choice, Cognitive Approach

\section{Introduction}

The tendency of transforming from resource-export economy to resource-innovation ("non-oil") economy (the tendency that is characteristic for today's Azerbaijan's economy) requires promotion of innovative activities in all levels of management - federal, regional, corporate and in the level of separate enterprises. In connection with this, the question of development and introduction of effective systems of innovation management, and in the first turn, systems of innovation management of enterprises (IME) which are the main constitutional elements of national economy, becomes essential.

In today's challenging economic conditions, the effectiveness of innovation enterprise strategies largely depends on decisions made at the initial (conceptual) stage of the innovation process, which is associated with the choice of the general direction of innovative development of enterprises.

Namely, at this stage, managers everywhere face serious difficulties arising from complex ill-structured character [1] of innovation choice problem.

Here opportunities for using known tools of IME support based on the traditional mathematical-statistical paradigm [2,
3] are extremely limited. Along with this, under conditions of unstable transferring economy and uninterruptedly growing competition the question of scientific support of this stage is becoming more and more important and may be assigned to the most essential questions of theory and practice of IME.

Methods modeling ill-structured problem situations developed in recent years basing on cognitive approach open new perspectives for solution of the question $[4,5]$. In the conditions of incomplete and inaccurate statistics, which is characteristic of an innovation practice, and in the continuously changing environment, the cognitive approach allows solving this problem on the qualitative level. We use IME cognitive models based on mental models of experts, advanced innovation experience of the industry, linguistic estimates of the parameters of the enterprise and environment, knowledge-based algorithms of scenario analysis of innovation situations.

The aim of the article is to present a methodology of using the cognitive approach at the early stage of IME strategy development associated with the choice of the general direction of innovative development of an enterprise. The proposed methodology fully meets the requirements of DSS-methodologies of the 21st century [3]. Methodology 
differs from the known schemes described in [6, 7]. Main differences is that, along with the use of the main provisions of cognitive approach, methodology takes into account

(1) deep semantics of IME subject area [2],

(2) reproductive character [8] of innovation processes, which are now mainly based on the best world practice,

(3) instrumental skills of modern knowledge-based technologies $[2,4,9]$,

(4) principles and methods of scenario analysis in non-monotonic dynamic environments $[10,11]$.

\section{Main Provision of Cognitive Approach}

\subsection{General Conception}

Cognitive approach is a method of analysis and managing problematic situations basing on formation and study of cognitive maps. Cognitive map is a structure (network) of cause and effect relations between the components of the system under survey and its surrounding environment, reflecting the mental understanding of expert(s) about the structure and functioning of this system.

The ontologies of cognitive map are:

1) basic factors (concepts) characterizing the system and its surrounding environment according to the management person(s),

2) as well as cause and effect relations between basic factors.

A specific feature of the cognitive modeling method differing it from traditional methods is the possibility of conducting multi-factor and multi-criteria analysis and management of development of ill-structured situations (combining vitally important stages of divergence, convergence and transformation of project cycle [8]) that is not possible through traditional mathematical calculations.

Cognitive modeling is a periodic process and consists of several interrelated stages main of which are: cognitive structuring of problematic knowledge and development of cognitive map of surveyed situation; structural analysis of cognitive map; scenario-based modeling of development of situation.

\subsection{Cognitive Structuring of Problematic Knowledge}

Identification of SWOT\&PEST-factors characterizing internal situation in the enterprise and external processes are influencing its development. The cognitive structuring stage is formed as a cognitive map (CM) describing a set of basic factors of internal and external environment of the enterprise and cause and effect relations between them.

At present general feature for all works of cognitive approach is a cognitive map as digraph (signed or weighed [9]) over a range of factors.

For each factor its value (or tendency of change) characterizing the subject, event or process associated with the given factor is determined. For cause and effect relations character and strength of interrelation between basic factors is determined. Values of appropriate variable are given on the basis of a linguistic scale, i.e. in words in a native language and each is denoted by a corresponding figure in the interval $[-1 ; 1]$.

In this stage on the basis of set of basic factors also are determined: subset of target and subset of manageable factors, also, initial values and tendencies of change of basic factors. Factors relating to the enterprise or to external environment, which the management of the enterprise may influence on, are selected as manageable factors.

\subsection{Structural Analysis of Cognitive Map}

This analysis is implemented to study structural features of $\mathrm{CM}$ which are important from the point of view of management practice. Such features include:

1) Consistency targets. The main point of the non-conflicting targets vector is to ensure that desired change of some target factors does not result in undesirable change of others.

2) Consistency targets and manageable factors. Managing the situation is the change of manageable factors to the extent that would result in desired change of target factors, i.e. in the direction of planned dynamics. In connection with this, effectiveness of influence of manageable factors on targets of the enterprise and conformity of manageable factors with the targets of the enterprise is surveyed. Acceptable effectiveness of manageable factors is determined by the degree and character of their influence on the target factors. Conformity of manageable factors with targets vector means that no change of them should cause change in any of the targets in undesired direction.

At present a range of mathematical methods of structural analysis of CM has been developed. However, in practice, structural solutions achieved through these formal and mathematical methods require interpretations in the subject area, which are not always possible.

\subsection{Scenario Modeling of Development of Situation}

This is conducted for comparative analysis of development of situation in different incoming managing impacts. Modeling may be conducted in self-development and managed development modes. Dynamics of development of situation is modeled using scenario-based "inference mechanism" (control mechanism for solution of the problem).

Developed by us "inference mechanism" $[10,11]$ is based on the

- "general theory of impulse processes" on digraphs (signed and weighted) [9],

- $\quad$ algorithms of strategic planning of knowledge-based solvers by the "direct wave" and by "reverse wave" $[12,13]$, 
- principles and methods of scenario planning $[14,15]$

The mechanism of this type removes many limitations of theoretical schemes and approaches the innovative practices to the leading postulates of pragmatic management:

Postulate 1. The management from the future [16].

Postulate 2. Knowledge-based processing of uncertainty $[17,18]$.

Postulate 3. The requisite variety of control mechanism [19].

Self-development implies maintaining existing tendencies of factors and in essence, it is extrapolation of current situation taking into account mutual influences of basic factors.

Managed development of situation implies purpose targeted influence on one or several manageable factors. Impulsive change of current value of the factor which is transferred to other factors through the chains of impacts serves as management.

\section{Features of Developing Cognitive Models of IME}

Opportunities of cognitive approach may be used for modeling different tasks of IME, and in the first turn, initial task of IME connected with formation of conceptual project of innovative development and directed towards achievement of established targets of the enterprise.

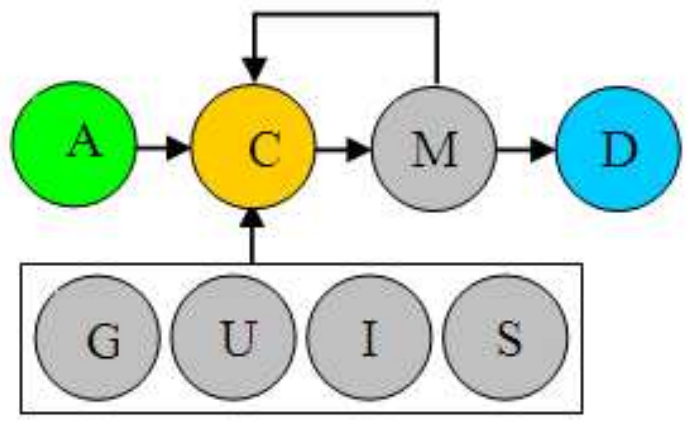

Figure 1. Cognitive IME models development methodology scheme.

Legend:

Stages of methodology

A. Macroeconomic and marketing analysis of the enterprise. Choice of the mode of the innovation development.

C. Cognitive structuring of innovation situation of IME. Design a cognitive map (CM).

M. Scenario-based analysis of alternative versions of innovative development of the enterprise (model experiments on $\mathrm{CM}$ ).

D. Choice a scenario of innovative development and formation of a portfolio of innovations.

Standards and reference base of CM of IME

G. Key modes of innovation development (OECD). Support tools. Cases of best innovation practice.

U. Reference List of bases factors of CM of IME.

I. Industry Catalogues of innovations necessary for realize manageable factors.

S. The integrity constraints of Cognitive Map (structural, parametric, temporal).
Our enough long experience (since 2002) in the field of cognitive technologies shows that in the process of developing cognitive models in production and economic spheres the use of not only and not such extent of explicit knowledge of management persons is extremely important (as it is introduced in the materials of Institute of Management Problems Russian Academy of Sciences [20], a leading scientific research institute in Russia in the field of cognitive technologies), as use of all "status knowledge" of the subject area reflecting both best international practice and specific nature of a particular enterprise. This extra-personal knowledge of the subject area is achieved from the sources such as books, articles in magazines, standards applicable to particular sectors and Technological Registers of world's leading companies in the given sector, analogical projects of leading companies and internet. Consequently, the question of reliability of cognitive models actively discussed in the works of the Institute of Management Problems are solved not only and not so much by reliable application of knowledge of management personal, as it is achieved through maximum use of "high-profile knowledge" in the subject area.

The need for development of appropriate methodology for developing cognitive models of IME was determined on the basis of these ideas. In presentations of cognitive approach general scheme of this methodology may be displayed as it is shown in Figure 1.

\section{Example}

Application of cognitive approach in developing models of IME has been described in the example of a machine-building company.

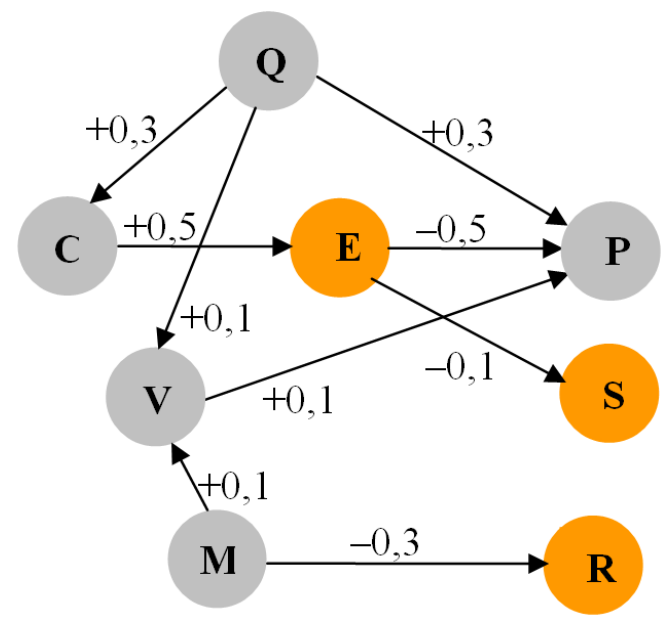

Figure 2. Cognitive map of an innovation enterprise (a fragment)

Figure 2 shows a piece of the cognitive map reflecting production and economic status (a version) of the enterprise.

Basic factors of $\mathrm{CM}$ are the following:

- $\quad$ Target factors: Earnings (E), Share in market (S), Risk (R) (risk of no realization of innovation project). 
- Manageable factors: Quality of product (Q), Price of product $(\mathrm{P})$, Production cost of product $(\mathrm{C})$, Sales value $(\mathrm{V})$, Occupation of a place in a new market (M).

For assessment of "initial values", "rates of change" and "degrees of mutual influences" of the CM factors the following linguistic scale has been applied (Table 1).

Types of innovation scenarios which may be formed through changing values of controlled factors are listed on the Table 2.

Scenarios organized by the second method of innovation (OECD [21]).

Designed cognitive map of IME may be researched through scenario-based "inference mechanism".

This mechanism enables to generate various versions of innovation activities of the enterprise, to assess their influences on the targets of the enterprise and basing on this, to choose the most effective direction of innovative development.

Table 1. Linguistic scale for assessment of value of factors and sign and interaction strength between factors

\begin{tabular}{cl}
\hline Scale elements & Linguistic assessment \\
\hline 0,1 & VERY_LOW | VERY_LITTLE | VERY_WEAK \\
0,3 & LOW | LITTLE | WEAK \\
0,5 & MEDIUM $\square$ MODERATE \\
0,7 & HIGH | BIG | STRONG \\
0,9 & VERY_HIGH|VERY_BIG $\mid$ VERY_STRONG \\
& 0,$2 ; 0,4 ; 0,6 ; 0,8-$ intermediate values \\
\hline
\end{tabular}

Table 2. Main scenarios of innovative development of enterprise (version)

\begin{tabular}{|c|c|}
\hline Innovation scenarios & Types of reproduction of product \\
\hline $\mathrm{S} 1: \mathrm{Q}_{0} \mathrm{E}_{0} \mathrm{C}_{0} \mathrm{~V}_{0} \mathrm{M}_{0}$ & Reproduction on a simple scale (without innovations) \\
\hline $\mathrm{S} 2: \mathrm{Q}_{1} \mathrm{E}_{0} \mathrm{C}_{0} \mathrm{~V}_{0} \mathrm{M}_{0}$ & Reproduction of a higher quality product on a simple scale \\
\hline $\mathrm{S} 3: \mathrm{Q}_{0} \mathrm{E}_{1} \mathrm{C}_{0} \mathrm{~V}_{0} \mathrm{M}_{0}$ & Simple scale reproduction of a product with lower prices \\
\hline $\mathrm{S} 4: \mathrm{Q}_{0} \mathrm{E}_{0} \mathrm{C}_{1} \mathrm{~V}_{0} \mathrm{M}_{0}$ & Simple scale reproduction of a product on the basis of resource saving technology \\
\hline S5: $\mathrm{Q}_{1} \mathrm{E}_{0} \mathrm{C}_{0} \mathrm{~V}_{1} \mathrm{M}_{1}$ & Complex reproduction of a new product for old and new markets \\
\hline S6: $\mathrm{Q}_{0} \mathrm{E}_{1} \mathrm{C}_{1} \mathrm{~V}_{1} \mathrm{M}_{0}$ & Complex reproduction of an old product produced on the basis of new technology \\
\hline $\mathrm{S} 7: \mathrm{Q}_{0} \mathrm{E}_{0} \mathrm{C}_{0} \mathrm{~V}_{0} \mathrm{M}_{1}$ & Simple scale reproduction of an old product for old and new markets \\
\hline n........... & 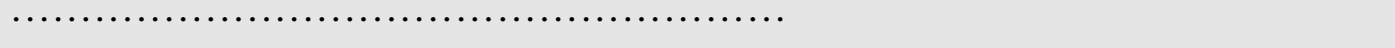 \\
\hline $\mathrm{S} n: \mathrm{Q}_{1} \mathrm{E}_{1} \mathrm{C}_{1} \mathrm{~V}_{1} \mathrm{M}_{1}$ & $\begin{array}{l}\text { Complex reproduction of new products produced on the basis of new technology for old and new markets (the most } \\
\text { complex reproduction) }\end{array}$ \\
\hline
\end{tabular}

Notes:

1. Index 0 means invariability of the value of the manageable factor (old version). Index 1 means variance of value of manageable factor. For example, improve of quality of the product $-\mathrm{Q}$, decline of price $-\mathrm{P}$, or production cost $-\mathrm{C}$, increase in sales volume $-\mathrm{V}$, extension of existing market or occupation of new market $-M$.

2. It is assumed that: a) if quality of the product is maintained, costs incurred by the customer remain unchanged, b) when quality of the product is improved, the rate of decrease of costs incurred by the customer is faster than the rate of increase of costs of the manufacturer, c) introduction of a new product on the basis of discoveries leads to improved quality and decrease of production cost of the product.

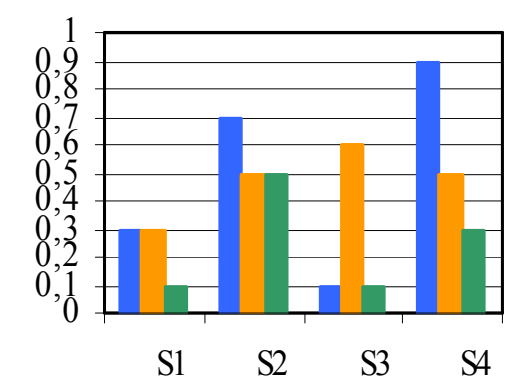

Earnings (E) $\square$ Share in market (S) $\square$ Risk (R)

Figure 3. Results of scenario-based analysis

Results of scenario-based analysis of some alternative variants of innovative development of enterprise are shown in Figure 3.
Specification of executed model experiments shows on the Table 3.

Thus, scenario-based analysis of a model allows to determining alternative perspectives of innovative development of the enterprise.

Realization of selected direction requires appropriate innovations. For this purpose, Technological Innovations Registers of leading companies may be used or Innovations Reference Catalogue may be developed for the companies of respective profile. They may be used for realization of selected scenario, consequent detailed (quantitative) analysis of scenario and formation of innovations portfolio included in innovation project of the enterprise. In the process of working on particular projects, we have developed such Catalogues (on the basis of best foreign technologies) for:

1. Specialized oil plant for production of lubricants, 
admixtures and special oils (purpose of project improving the quality of products),

2. Poultry farm of one of holding companies (purpose of project is to expand assortments of products, increasing share in the market),
3. Steel works compound (purpose of project is using as raw material scrap metal and metal discard of many years of upgraded companies badly impacting ecology of respective region, supply of high-quality iron sheets to metallurgic plants in oil and gas sector).

Table 3. Specification of executed model experiments

1. Alternative scenarios of innovation development (according to Table 2)

1.1. "Mode of self-development"

1.2. "Modes of managed innovation development"

2. Management type:

3. Initial values of the objective factors (on a scale of Table 1)

4. The initial values of manageable factors (on a scale of Table 1)

5. Pulsed impacts on the priority manageable factors (on a scale of Table 1)
$\mathrm{S} 1: \mathrm{Q}_{0} \mathrm{P}_{0} \mathrm{C}_{0} \mathrm{~V}_{0} \mathrm{M}_{0}$

S2: $\mathrm{Q}_{1} \mathrm{P}_{0} \mathrm{C}_{0} \mathrm{~V}_{0} \mathrm{M}_{0} ; \quad \mathrm{S} 3: \mathrm{Q}_{0} \mathrm{P}_{1} \mathrm{C}_{0} \mathrm{~V}_{0} \mathrm{M}_{0} ; \quad \mathrm{S} 4: \mathrm{Q}_{0} \mathrm{P}_{0} \mathrm{C}_{1} \mathrm{~V}_{0} \mathrm{M}_{0}$

Single-step scenario. The simple pulsed process

$\mathrm{E}=0,3 ; \mathrm{S}=0,3 ; \mathrm{R}=0,1$

$\mathrm{Q}=0,3 ; \mathrm{P}=0,5 ; \mathrm{C}=0,7 ; \mathrm{V}=0,5 ; \mathrm{M}=0,3$

$\mathrm{Q}_{1}=+0,3 ; \mathrm{P}_{1}=-0,1 ; \mathrm{C}_{1}=-0,3$

\section{Conclusion}

Cognitive models described in the article may be referred to a new generation of IME support tools. Models allow choice concept of innovative development of enterprises in complex and turbulent business environment.

Along with this, the experience we have gained show that creation of adequate and effective cognitive models (as well as in the case of other knowledge-based technologies [12, 13] depends not only on representation and inference formalisms used in these models, but also on completeness and quality of knowledge which are laid in the knowledge base of these models.

Identification of such knowledge requires thorough study of deep semantics of the subject area and the specificity of functioning of each particular enterprise.

In general theoretical terms considered above cognitive technology apparently can viewed as a publicly available multidisciplinary platform which enables one to:

1) unite instrumental potentials known paradigms of supporting innovation processes in SMEs [2];

2) adapt them to the conditions of a particular enterprise and

3) efficiently use on the step of afferent synthesis innovation strategies [22] in conditions of turbulent business environment and "reflexivity" decision-makers, inevitable in situations complex choices [23, 24, 25].

Though cognitive methodology alone does not assure the success in innovation development process, they are enabling factors and can support the creation of innovation strategies, reasoning, insights and communication.

The adoption of such techniques, facilitating the codification of the characteristics of the innovation development process might be particularly useful in those environments where, due to the lack of specialized resources, it is difficult to structure all of the information related to the innovation process and to exploit the related benefits and opportunities. Moreover, formal techniques and methods can have a didactic role.

They can teach managers how to develop innovations and also make them more sensible towards innovation, so reducing their tendency to act based solely on intuitions and routine rather than structured knowledge.

Cognitive maps can be used to structure the decision process, capture the decisions made about products and create a sort of organizational memory and can be used to capture the different interpretations held by various players in the innovation process and support the strategy development.

Brief description of the cognitive approach given in this article, to a certain extent, have demonstration character.

Beyond the scope of article remained many problems arising in developing and introduction of modern knowledge-based technologies [13, 9, 24, 26, 27, 3]. This "the problem feasibility" of developing cognitive models, "problem of adequacy" of models, "problem of robustness", "problem of testing", "problem of traps" arising during operation with experts on the stages of models development and testing and others.

Nevertheless, we hope that the article gives some presentation of the possibilities of cognitive models, and the prospects for their use in real applications of innovative practices.

Projects carried out by us in the field of cognitive technologies, awarded the Diploma of the Russian Academy of Sciences and a Grant of the International Science Foundation for Economic Research acad. N. P. Fedorenko (Project 2003-041).

\section{References}

[1] H. Simon, A. Newell. "Heuristic problem solving: the next advance in operational research", Operations Research. Vol. 6, Jan. 1958. pp. $3-10$. 
[2] S. Barbara, C. Garavelli, and K. Crowston. "Methods for modeling and supporting innovation processes in SMEs", European Journal of Innovation Management, Vol. 8 No. 1, 2005. pp. 120-137.

[3] G. Marakas. Decision Support Systems in the twenty-first century. Upper Saddle River, New Jersey: Prentice Hall, 1999.

[4] Schellinck J., Webster R. "Cognitive models: Understanding their critical role as explanatory and predictive hypothesis generators in cognition research", IEEE Proc. of the Intern. Conf. on Cognitive Modeling ICCM*2013. Canada, Ottawa, 2013.

[5] IEEE Proc. of the Intern. Conf. on Cognitive Modeling (ICCM) Series ICCM 2013: Ottawa, Canada (proceedings) ICCM 2012: Berlin, Germany (proceedings) ICCM 2010: Philadelphia, USA (proceedings) CCM 2009: Manchester, UK (proceedings) CCM 2007: Ann Arbor, USA (proceedings) ICCM 2006: Trieste, Italy (proceedings) ICCM 2004: Pittsburgh, USA (proceedings) ICCM 2003: Bamberg, Germany (proceedings) ICCM 2001: Fairfax, USA (proceedings) ICCM 2000: Groningen, Netherlands (proceedings) ECCM 98: Nottingham, UK (proceedings) EuroCog 1996: Berlin, Germany (proceedings)

[6] Russell, R.D. "Developing a process model of entrepreneurial systems: a cognitive mapping approach", Entrepreneurship Theory and Practice, 1999. Vol. 23 No. 3, pp. $65-85$.

[7] J. Swan. "Exploring knowledge and cognitions in decisions about technological innovation: mapping managerial cognitions". Human Relations. 1995. Vol. 48 No. 11, pp. 1241-70.

[8] J. Jones. Design Methods. London: Architecture Design and Technology Press. 1991.

[9] F. Roberts. Discrete Mathematical Models with Application to Social, Biological and Environmental Problems. New Jersey: Prentice-Hall, Inc.1976.

[10] R. Karayev et al. "Forming of corporate enterprise policies by means of fuzzy cognitive maps", Trans. of the Nat. Acad. of Sci. of Azerbaijan. Series of phys.-math. and techn. sciences. V. XXIII, No 2, 2004 (in Russian).

[11] R. Karayev et al. "Models of scenario analysis", Trans. of the Nat. Acad. of Sci. of Azerbaijan. Series of phys.-math. and techn. sciences. V. XXIII, No 3, 2004 (in Russian).
[12] D. Pospelov. Situational Management: Theory and Practice. Moscow: Nauka, 1986. (in Russian).

[13] D. Waterman. Guide to Expert Systems. Addison-Wesley Publ. Co., Inc. 1986.

[14] B. Balston, B., and I. Wilson. The Scenario Planning Handbook: Development strategies in uncertain times. Harlow, Pearson. 2006.

[15] M. Lindgren, and H. Bandhold. Scenario planning. The Link Between Future and Strategy. New York: Palgrave MacMillan. 2009, 204 p.

[16] I. Ansoff. Corporate Strategy: An Analytical Approach to Business Policy for Growth and Explanation. New York: McGraw Hill. 1965.

[17] R. Grant. "Toward a knowledge-based theory of the firm", Strategic Management Journal, 1996. No17 (Winter special issue): $109-122$.

[18] N. Anand, H. Gardner and T. Morris. "Knowledge-based innovation: Emergence and embedding of new practice areas in management consulting firms", Academy of Management Journal. 2007. Vol. 50, pp. 406-428.

[19] W. Ashby. An Introduction to Cybernetics. London: Chapman and Hall. 1956.

[20] Proc. of the Intern. Conf. "Cognitive Analysis and Management of Development of Situations". CASC'2007. M.: Institute of Management Problems, Russian Academy of Sciences (http://www.ipu-conf.ru, http://CASC\&apos;2007) (in Russian).

[21] Organization for Economic Co-operation and Development (OECD). Science, Technology and Industry Outlook. 2008 OECD Code: $922008108 \mathrm{E} 5$ (http://www.oecd.org/html).

[22] H. Mintzberg. The Rise and Fall of Strategic Planning. New York: Free Press. 1994. 416 p.

[23] G. Soros. The Alchemy of Finance. Wiley. 2003. 416 p.

[24] D. Dorner. The Logic of Failure: Recognizing and Avoiding Error in Complex Situations. Basic Books Publ. 1996. 222 p.

[25] S. Makridakis. Forecasting, planning, and strategy for the 21st century. New York: Free Press. 1990, 293 p.

[26] V. Margolis. The Politics of the Artificial: Essays on Design and Design Studies. University of Chicago Press. 2002. 198 p.

[27] C. Holsapple, and A. Whinston. Decision Support Systems: A Knowledge-based Approach. Minneapolis: West Publishing Co. 1996. 254 p. 